Original article

\title{
General population's eagerness and knowledge regarding basic life support: A community based study in Jakarta, Indonesia
}

\author{
Raymond Pranata ${ }^{\mathrm{a}, *}$, Wendy Wiharja ${ }^{\mathrm{a}}$, Abraham Fatah ${ }^{\mathrm{a}}$, Muhammad Yamin ${ }^{\mathrm{b}}$, \\ Antonia Anna Lukito ${ }^{c}$ \\ ${ }^{a}$ Faculty of Medicine, Universitas Pelita Harapan, Tangerang, Banten, Indonesia \\ ${ }^{\mathrm{b}}$ Division of Cardiology, Department of Internal Medicine, Faculty of Medicine Universitas Indonesia/Cipto Mangunkusumo National General Hospital, Jakarta, Indonesia \\ ${ }^{\mathrm{c}}$ Department of Cardiology and Vascular Medicine, Siloam Hospitals Lippo Village - Faculty of Medicine, Universitas Pelita Harapan, Tangerang, Indonesia
}

\section{A R T I C L E I N F O}

\section{Keywords:}

Basic life support

General population

Cardiopulmonary resuscitation

Automated external defibrillator

Cardiac arrest

\begin{abstract}
A B S T R A C T
Background: Basic life support (BLS) performed by general population improves outcomes in cardiorespiratory collapse. This community-based study aims to measure the general population's eagerness in learning BLS, knowledge regarding early recognition, and use an automated external defibrillator.

Methods: This was a cross-sectional community-based study in Jakarta using questionnaire. Numerous questions asked through a questionnaire in order to evaluate the general population's eagerness and knowledge about basic life support.

Results: There were 303 respondents in this study. Most respondents stated that knowledge about BLS is important and was eager to learn; however, only $39.6 \%$ of respondents have ever done BLS training. 59.4\% of respondents have ever looked for information or read about BLS. $63.6 \%$ of respondents chose to call an ambulance for the first reaction, while $36,5 \%$ of respondents preferred to look for a pulse. Most of the respondents know to check the carotid pulse in the neck. $77.4 \%$ of respondents know that chest compression was done on mid-chest. $81.5 \%$ of respondents agreed that CPR was preferably done repeatedly in a specific rhythm, but giving one despite the method is better than none. Only $49.5 \%$ of respondents wanted to give mouth-to-mouth ventilation. Most respondents thought that they are not allowed to use AED, and only a small proportion had seen AED in public.

Conclusion: Most of the respondents agreed that BLS is important. Respondents have satisfying knowledge about how to react while encountering an unconscious person. Most respondents have not seen AED and most likely didn't know how to use it.
\end{abstract}

\section{Background}

Basic life support (BLS) performed by general population improves outcomes in cardiorespiratory collapse, yet less than $1 \%$ of the general population can perform it effectively. ${ }^{1}$ Each year, more than 350,000 individuals in North America and 300,000 individuals in Europe suffer from out-of-hospital cardiac arrest. ${ }^{2}$ As time passes, the number of patients with a shockable rhythm decreases, and as a result, the chance of survival diminishes with 7-10\% for every minute that passes without intervention. ${ }^{3}$ Emergency management includes cardiopulmonary resuscitation (CPR) and the use of an automated external defibrillator (AED). When both of these performed, the survival rate is $75 \%$ higher than CPR alone. ${ }^{4}$ This community-based study aims to measure the general population's eagerness in learning BLS, knowledge regarding early recognition, and use an automated external defibrillator. To the best of our knowledge, this is the first study that assessed the eagerness and knowledge of basic life support in Indonesia.

\section{Methods}

\subsection{Study design}

This was a cross-sectional study conducted in June 2016. For this study, we used a questionnaire that was distributed to potential participants through simple random sampling. The questionnaire was given randomly to non-medical personnel in public places across North

\footnotetext{
* Corresponding author.

E-mail addresses: Raymond_pranata@hotmail.com (R. Pranata), wiharja.wendy@gmail.com (W. Wiharja), Abraham.fatah@gmail.com (A. Fatah), muhyam511@gmail.com (M. Yamin), lukito_ant@yahoo.com (A.A. Lukito).
} 
Jakarta, West Jakarta, Central Jakarta, East Jakarta, and South Jakarta. We included respondents that gave their consent to fill the questionnaire and has an age of $>17$ years old. We excluded potential respondents that were from a medical background (medical doctors, allied professional, paramedics, and midwives). We collected 61 respondents from North Jakarta, 60 from West Jakarta, 61 from Central Jakarta, 60 from East Jakarta, and 61 from South Jakarta.

\subsection{The questionnaire}

There were numerous questions asked through a questionnaire in order to evaluate the general population's eagerness and knowledge about basic life support. The questions were in Indonesian Language and were designed as multiple choice questions. This was a three-segment questionnaire. The first segment evaluated the characteristics of the respondents and their opinion on BLS; which includes a question on whether they thought that BLS is important, whether they are eager to learn, their experience in BLS training, and have they ever looked up for information on BLS. The second segment assesses the basic knowledge if BLS; this segment contains questions on what will they respond with should they find someone with probable cardiac arrest, location to check for a pulse, site for chest compression, their methods, their opinion on mouth-to-mouth ventilation. The third segment consists of questions directed at the knowledge of AED; this includes the place they have ever seen an AED (if any) and their stance on the use of AED by non-medical personnel.

\subsection{Statistical analysis}

All statistical analysis was performed using IBM SPSS Statistics for Windows, Version 24.0. Armonk, NY: IBM Corp) and Microsoft Excel software. Description of the sample was performed using descriptive statistics option in the SPSS; most of the data in this study is presented as [number (\%)].

\section{Results}

We approached 350 people and asked for consent to fill our questionnaire, and there were 303 respondents (160 males, and 143 females) that consented to fill the questionnaire. Majority of respondents' level of education was high school (58\%) and undergraduate (38\%). Most of the respondents were 17-30 years old (63.7\%) (Table 1). Among the participants, there were 294 (97\%) respondents that thought knowledge on BLS is important, and 222 (73.5\%) respondents were eager to learn about BLS. Despite a high number of those who were eager to learn, only $120(38.6 \%)$ of respondents have ever participated in BLS training. 180 (59.4\%) respondents have ever looked for information on BLS. $192(63.6 \%)$ respondents chose to call an ambulance for the first reaction while $111(36,4 \%)$ respondents preferred to look for a pulse. $284(93.7 \%)$ respondents chose to check carotid pulse, and other $19(6.3 \%)$ respondents chose to look for pulse elsewhere. 233 (77.4\%) respondents know that chest compression was done on midchest. $246(81.5 \%)$ respondents agreed that CPR was preferably done

Table 1

Baseline characteristics of the respondents participating in the survey.

\begin{tabular}{lll}
\hline \multirow{2}{*}{ Baseline Characteristics } & & Percentage (\%) \\
\hline \multirow{2}{*}{ Gender } & Male & 52.8 \\
\multirow{3}{*}{ Age } & Female & 47.2 \\
& $17-30$ & 63.7 \\
\multirow{3}{*}{ Level of Education } & $30-40$ & 29.7 \\
& $>40$ & 9.9 \\
& High School & 58 \\
& Undergraduate & 38 \\
& Others (Junior high, postgraduate) & 4
\end{tabular}

Table 2

Subjects response to items in the questionnaire.

\begin{tabular}{|c|c|c|}
\hline Items & $\begin{array}{l}\text { Yes/Correct } \\
\text { Answer (\%) }\end{array}$ & $\begin{array}{l}\text { No/Incorrect } \\
\text { Answer (\%) }\end{array}$ \\
\hline \multicolumn{3}{|c|}{ General Population's Eagerness in Learning Basic Life Support } \\
\hline BLS is important & 97 & 3 \\
\hline Eager to Learn & 73.5 & 26.5 \\
\hline Ever done BLS training & 61.4 & 38.6 \\
\hline Ever looked for information or read about BLS & 59.4 & 40.6 \\
\hline \multicolumn{3}{|c|}{ General Population's Early Response to Cardiac Arrest } \\
\hline Method of pulse checking & 93.7 & 6.3 \\
\hline Chest compression site & 77.4 & 22.6 \\
\hline $\begin{array}{l}\text { Preferably done repeatedly in a specific } \\
\text { rhythm, but better than none }\end{array}$ & 81.5 & 18.5 \\
\hline $\begin{array}{l}\text { Willing to give mouth-to-mouth ventilation } \\
\text { when needed }\end{array}$ & 49.5 & 50.5 \\
\hline \multicolumn{3}{|l|}{ General Population's Knowledge about AED } \\
\hline Everyone can use an AED & 34.7 & 65.3 \\
\hline $\begin{array}{l}\text { Should be used indiscriminately on every } \\
\text { unconscious person, suspected of having } \\
\text { a cardiac arrest }\end{array}$ & 37.3 & 62.7 \\
\hline Have seen AED in Public Places & 17.2 & 82.8 \\
\hline
\end{tabular}

Description: AED = Automated External Defibrillator; BLS = Basic Life Support.

repeatedly in a specific rhythm, but giving one despite the method is better than none while 57 (18.5\%) disagreed. Only 150 (49.5\%) respondents willing to give mouth-to-mouth ventilation if needed. 198 (65.3\%) respondents answered 'only paramedics are allowed to use AED' while 105 (34.7\%) of them think otherwise. 251 (82.8\%) respondents have never seen AED in public, only 53 (17.2\%) of them have seen AED at the hospital (33 respondents/62.3\%), airport, and mall. $190(62.7 \%)$ respondents disagreed that AED should be used indiscriminately on every unconscious person suspected of having a cardiac arrest (Table 2).

\section{Discussions}

Majority of respondents (97\%) wanted to know BLS better, and more than half of them $(73.5 \%)$ wanted to learn about it which were satisfying. Most of the respondents correctly answer that pulse can be examined by palpating carotid pulse. Correct method of pulse examination may avoid unnecessary CPR in non-cardiac arrest and unnecessary delay CPR in true cardiac arrest. $77,4 \%$ know that $C P R$ is performed on mid-chest, which is also satisfying. A high-quality CPR is critical, an insufficient depth and pace of compression can reduce survival by $30 \%$ respectively. ${ }^{5-7}$ While this questionnaire is unable to determine the quality of CPR performed by the respondents, knowing the correct method is an essential first-step in BLS. Only $49.5 \%$ wanted to perform mouth-to-mouth ventilation; however, this is not a concern because according to L. Cabrini et al., a bystander compression-only CPR should be recommended as the preferred CPR technique performed by untrained bystander hence early recognition and willingness to initiate CPR is more important than a delaying CPR to finding someone who is willing to perform mouth-to-mouth ventilation. ${ }^{8}$ This should be known to the public, which will increase their willingness and shorter period of arrest to the first response. $65,3 \%$ didn't know that everyone can use AED, which is a major concern because we need to rely on a bystander to initiate. $62,7 \%$ think AED should not be used in those unconscious person suspected to be in cardiac arrest, while it is true that electrical shocks are not always needed in those, AED should be attached to detect. 82,8\% have never seen AED and the majority of those who see only in hospitals these reflect either poor availability of AED in public places or people are not aware of its presence. We would like to highlight that only small proportion of people thought that they can use AED and in real-life situation, these people might not be able to find AED due it's to poor availability. Should the bystanders are be able to find AED, it is yet to be known whether they can operate the machine correctly (only a small percentage has done BLS training), whereas 
early defibrillation by AED is the most critical intervention for out-ofhospital cardiac arrest which survival proportions $>50 \%$ if done. According to Bcekgaard et al. defibrillation by non-dispatched lay first responders had the highest impact on survival (almost two-fold) compared to EMDC-dispatched professional first responders. ${ }^{3}$ Hence, poor knowledge regarding the use of AED is one of the major issues that may affect the survival of out-of-hospital cardiac arrest.

\section{Conclusions}

Most of the respondents agreed that BLS is important and are eager to learn about it. Respondents have satisfying knowledge about how to react while encountering an unconscious person; this, however, does not directly translate to fluency in a real-life situation. Most of the respondents think that they are not allowed to use AED and only a minority of them had seen AED in public, and most of them are in hospitals meaning that AED is limited in public places. Mass media and public figure should take part in encouraging people to learn about basic life support.

\section{Strengths and limitations of the study}

The strength of our study is that this paper is, to the best of our knowledge, the first to describe the general awareness of BLS in Indonesia. Hence, this is the first article to provide insight on BLS among the general population in Indonesia. We also took the samples throughout different regions of Jakarta to minimize bias of taking the samples from a specific place. The limitation of our study is that the sample is small compared to the size of the population in Jakarta. This study did not include other parts of Indonesia. It should be noted that Jakarta is currently (at the time this paper was written), capital and the largest city in Indonesia, hence, did not reflect the knowledge across the nation. This questionnaire relies on the honesty of respondents on answering these questions. Answering the questionnaire correctly does not reflect fluency in a real-life situation.

\section{Declaration of competing interest}

The authors declare that they have no competing interests.

\section{Acknowledgments}

We would like to thank the participants of this study.

\section{Abbreviations}

AED

BLS

Automated External Defibrillator

CPR Basic Life Support

Cardiopulmonary Resuscitation

\section{Declarations}

Ethics approval and consent to participate

Not Applicable.

Consent for publication

Not Applicable.

Funding

No source of funding.

\section{References}

1. Connolly M, Toner P, Connolly D, McCluskey DR. The 'ABC for life' programme-teaching basic life support in schools. Resuscitation. 2007;72(2):270-279. https://doi.org/10.1016/j.resuscitation.2006.06.031.

2. Atwood C, Eisenberg MS, Herlitz J, Rea TD. Incidence of EMS-treated out-of-hospital cardiac arrest in Europe. Resuscitation. 2005;67(1):75-80. https://doi.org/10.1016/j. resuscitation.2005.03.021.

3. Bækgaard JS, Viereck S, Møller TP, Ersbøll AK, Lippert F, Folke F. The effects of public access defibrillation on survival after out-of-hospital cardiac arrest. Circulation. 2017;136(10):954-965. https://doi.org/10.1161/CIRCULATIONAHA.117.029067.

4. Mozaffarian D, Benjamin EJ, Go AS, et al. Heart disease and stroke statistics-2016 update. Circulation. 2016;133(4) https://doi.org/10.1161/CIR.0000000000000350.

5. Meaney PA, Bobrow BJ, Mancini ME, et al. Cardiopulmonary resuscitation quality: improving cardiac resuscitation outcomes both inside and outside the hospital. Circulation. 2013;128(4):417-435. https://doi.org/10.1161/CIR.0b013e31829d8654.

6. Abella BS, Sandbo N, Vassilatos P, et al. Chest compression rates during cardiopulmonary resuscitation are suboptimal. Circulation. 2005;111(4):428-434. https:// doi.org/10.1161/01.CIR.0000153811.84257.59.

7. Stiell IG, Brown SP, Christenson J, et al. What is the role of chest compression depth during out-of-hospital cardiac arrest resuscitation?*. Crit Care Med. 2012;40(4):1192-1198. https://doi.org/10.1097/CCM.0b013e31823bc8bb.

8. Cabrini L, Biondi-Zoccai G, Landoni G, et al. Bystander-initiated chest compressiononly CPR is better than standard CPR in out-of-hospital cardiac arrest. HSR Proc Intensive Care Cardiovasc Anesth. 2010;2(4):279-285http://www.ncbi.nlm.nih.gov/ pubmed/23439400. 